\title{
EFFECTS OF CASTRATION AT BIRTH IN HAMSTERS OF BOTH SEXES ON LUTEINIZATION OF OVARIAN IMPLANTS, OESTROUS CYCLES AND SEXUAL BEHAVIOUR
}

\author{
HEIDI H. SWANSON \\ Department of Anatomy, University of Birmingham
}

(Received 21st July 1969)

Administration of testosterone propionate (TP) to female golden hamsters within a few days of birth prevents the appearance of oestrous cycles and corpora lutea (Swanson, 1966) and results in depression of female sexual behaviour (Swanson \& Crossley, 1969). The low level of receptivity is attributed not so much to a deficiency in ovarian secretion as to a decreased responsiveness to female hormones. In contrast to normal females, in which very little male behaviour can be elicited after ovariectomy and prolonged treatment with TP during adult life, females which had received as little as $10 \mu \mathrm{g}$ TP as infants responded to such a régime by frequently mounting other females and showing patterns of behaviour resembling attempts at intromission.

Male hamsters castrated as adults and given oestrogen and progesterone are treated as females by intact males and respond by marked lordosis (Swanson \& Crossley, 1969). Lordosis is not evoked in males which have received TP as infants. The fact that female sexual behaviour can be suppressed in both sexes and male behaviour enhanced in females by giving small doses of TP at birth suggests that endogenous secretion of androgen in the infant hamster is very low and apparently insufficient to 'defeminize' the male. The rôle of the infant testis in sexual differentiation has been further investigated in the present study by observing the effects of neonatal castration on the oestrous rhythm and on sexual behaviour.

Infant hamsters of both sexes were castrated under cold anaesthesia within $48 \mathrm{hr}$ of birth; control litter mates were sham-operated. Cannibalism by the mothers was frequent, but sixteen males and fourteen females survived for experimental study. Animals were weighed weekly after weaning. Adult males are generally smaller than females; the eight males castrated at birth only grew to the same size as the intact females, but the growth of the seven females ovariectomized at birth was not affected (Text-fig. 1). Previous observations have shown that castration of males at later ages results in a rapid acceleration of growth until female size (weight and length) is reached (Swanson, 1967). Body size is, therefore, under the direct influence of testicular secretion after puberty and not subject to an 'organizational' action of androgens on growth centres at birth. 
At 130 days, the intact animals of both sexes were gonadectomized. All the animals (those gonadectomized as infants or as adults) then received an implant of half an ovary under the left kidney capsule. Three weeks later, the females were examined daily for evidence of vaginal cyclicity, and mating tests for female behaviour were carried out on all animals. The testing procedure has already been described (Swanson \& Crossley, 1969); briefly, it consisted of placing the test animal in an observation cage with a vigorous male for $10 \mathrm{~min}$ and recording the latency, duration and intensity of lordosis. Tests were begun on the same day in all animals and repeated for 4 days consecutively so that behaviour could be correlated with each of the 4 days of the oestrous cycle. A

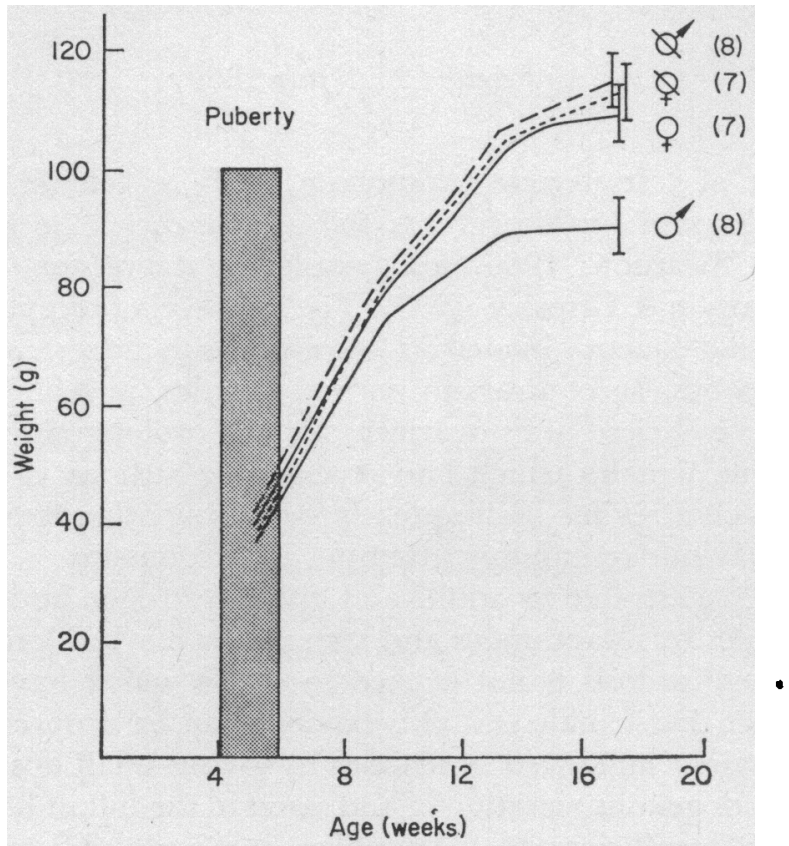

TEXT-FIG. 1. Effect of neonatal gonadectomy on the growth of hamsters. The age range during which puberty normally occurs is indicated by the stippled column. The number in parentheses is the number of animals per treatment group.

second series of tests was then carried out and the ovarian implants were removed from cyclic animals on the day after exhibition of lordosis in order to see whether fresh corpora lutea were present. If lordosis was absent or irregular, the implant was removed on the last day of testing.

A schematic presentation of typical responses is shown in Text-fig. 2. Five out of seven females ovariectomized as adults (adult castrates) and three out of seven ovariectomized at birth (infant castrates) showed 4-day vaginal cycles and lordosis only on the day of vaginal oestrus. The ovarian implants contained luteinized tissue. The acyclic animals were sexually unresponsive and no ovarian tissue could be found. The post-oestrous vaginal discharge was less copious in infant castrates but sexual behaviour was similar to that of adult castrates. 
By contrast, in the male, adult castrates from which ovarian implants were recovered (six out of eight) responded to the attention of normal males by marked lordosis on all the consecutive test days. Infant castrate males with viable implants (seven out of eight), on the other hand, showed lordosis every 4 th day and thus resembled females. All the implants were luteinized. It therefore seems that removal of the testes within $48 \mathrm{hr}$ of birth resulted in cyclic release of gonadotrophins to which the ovarian implants responded by cyclic secretion of the hormone complex necessary for the exhibition of sexual behaviour. In males whose testes were left in situ until shortly before ovarian

\begin{tabular}{|c|c|c|c|c|c|}
\hline \multirow{3}{*}{ Sex } & \multirow{3}{*}{$\begin{array}{l}\text { Age at } \\
\text { gonadectomy }\end{array}$} & \multicolumn{4}{|c|}{$\begin{array}{l}\text { Mating behaviour } \\
\text { after gonadectomy }\end{array}$} \\
\hline & & With ovarian & \multicolumn{3}{|c|}{ Without ovarian implant } \\
\hline & & & No hormones & $\begin{array}{l}\text { Oestrogen and } \\
\text { progesterone }\end{array}$ & $\begin{array}{c}\text { Testosterone } \\
\text { propionate }\end{array}$ \\
\hline \multirow{2}{*}{ Female } & Adult (7) & & $=-$ & & \\
\hline & Infant (7) & & $--1--1-n$ & & \\
\hline \multirow{2}{*}{ Male } & Adult (8) & & & & \\
\hline & Infant (8) & & $m=m=m=0$ & & \\
\hline
\end{tabular}

TExT-FIG. 2. Mating behaviour of hamsters gonadectomized at birth or as adults. The number in parentheses is the number of animals per treatment group. The figure of a female in lordosis indicates female behaviour and the figure of a male mounting indicates male behaviour. Tests for female behaviour in animals with ovarian implants and in those without implants or hormones were carried out on 8 consecutive days: the vertical bars indicate the days on which lordosis was shown. All animals showed lordosis on the single day on which they were tested after oestrogen and progesterone treatment. The triangle indicates exhibition of male behaviour after a course of testosterone propionate treatment.

tissue was implanted, the ovarian implants continuously secreted hormones in the correct balance and in sufficient quantity to allow sexual receptivity to be exhibited every day. It seems doubtful whether the luteinized appearance of the implanted ovaries indicated ovulation, since the luteinization was rather diffuse and more suggestive of theca luteinization than corpus luteum formation. This type of luteinization has been described in male rats and dissociated from ovulation (Harris, 1964).

Two weeks after removal of the implants, all animals were tested on 4 days consecutively for residual female behaviour with active males and also for any evidence of male behaviour with receptive females. Except for occasional transient lordosis, neither female nor male behaviour was shown by any of the animals. All animals were then injected with $25 \mu \mathrm{g}$ oestradiol benzoate and $0.5 \mathrm{mg}$ progesterone $24 \mathrm{hr}$ later and tested for female behaviour. All showed marked receptivity with no difference in behaviour attributable to sex or age at castration. 
A course of treatment of $0.5 \mathrm{mg}$ TP daily for 13 days was then begun and the animals tested for male behaviour. None of the females showed any male behaviour after testosterone treatment, nor did males castrated as infants. Normal male behaviour was restored in adult castrates. The difficulty in eliciting male behaviour in female hamsters confirms previous findings (Swanson \& Crossley, 1969). The refractoriness to treatment with TP during adult life of males whose testes had been removed at birth indicates that the infant testis is necessary for the development of the capacity to respond to male hormones as adults.

In assessing the rôle of hormones in infancy in the organization of sexual function and behaviour, it is instructive to compare different species. In contrast to hamsters, it is difficult to elicit female behaviour in male rats but female rats often show spontaneous male behaviour (Beach, 1942, 1943). Male rats castrated at birth are bisexual in that both female and male behaviour can be obtained after giving the appropriate hormones (Harris, 1964; Feder, Phoenix \& Young, 1966; Grady, Phoenix \& Young, 1965; Whalen \& Edwards, 1966). This has led to the conclusion that the main action of the infant testis is to suppress female behaviour rather than to enhance male behaviour (Gerall, Hendricks, Johnson \& Bounds, 1967; Whalen \& Edwards, 1967). The present study has shown that, in hamsters, the infant testis does not suppress female behaviour but is necessary for the expression of male behaviour. The oestrous rhythm is suppressed in both species. The ovaries do not seem to play any rôle in the organization of cyclicity or behaviour.

\section{REFERENCES}

BEACH, F. A. (1942) Male and female mating behaviour in prepuberally castrated rats treated with androgens. Endocrinology, 31, 673.

BEAGH, F. A. (1943) Effects of injury to the cerebral cortex upon the display of masculine and feminine mating behaviour by female rats. F. comp. Psychol. 36, 169 .

Feder, H. H., Phoenix, C. H. \& Young, W. C. (1966) Suppression of feminine behaviour by administration of testosterone propionate to neonatal rats. F. Endocr. 34, 131.

Gerali, A. A., Hendricks, S. E., Johnson, L. L. \& Bounds, T. W. (1967) Effects of early castration in male rats on adult sexual behaviour. F. comp. physiol. Psychol. 64, 206.

Grady, K. L., Phoenix, C. H. \& Young, W. C. (1965) Role of the developing rat testis in differentiation of the neural tissues mediating mating behaviour. F. comp. physiol. Psychol. 59, 176.

HARRIs, G. W. (1964) Sex hormones, brain development and brain function. Endocrinology, 75, 627.

Swanson, H. H. (1966) Modification of the reproductive tracts of hamsters of both sexes by neonatal administration of androgen or oestrogen. F. Endocr. 36, 327.

Swanson, H. H. (1967) Effects of pre- and post-pubertal gonadectomy on sex differences in growth, adrenal and pituitary weights of hamsters. $\mathcal{7}$. Endocr. $39,555$.

Swanson, H. H. \& Crossley, D. A. (1969) Sexual behaviour in the golden hamster and its modification by neonatal administration of testosterone propionate. Proc. Int. Conf. Horm. Development. Eds. M. Hamburgh and E. J. W. Barrington. The National Foundation, N.Y. (in press).

Whalen, R. E. \& Edwards, D. A. (1966) Sexual reversibility in neo-natally castrated male rats. $\mathcal{F}$. comp. physiol. Psychol. 62, 307.

Whalen, R. E. \& Edwards, D. A. (1967) Hormonal determinants of the development of masculine and feminine behaviour in male and female rats. Anat. Rec. 157, 173. 